American Journal of Pharmaceutical Education 2017; 81 (4) Article 75.

\title{
RESEARCH
}

\section{Assessment of Burnout and Associated Risk Factors Among Pharmacy Practice Faculty in the United States}

\author{
Shareen Y. El-Ibiary, PharmD, ${ }^{a}$ Lily Yam, PharmD, ${ }^{\mathrm{b}}$ Kelly C. Lee, PharmD, MAS ${ }^{\mathrm{c}}$ \\ ${ }^{a}$ Glendale Midwestern University College of Pharmacy, Glendale, Arizona \\ ${ }^{\mathrm{b}}$ Loma Linda University School of Pharmacy, Loma Linda, California \\ ${ }^{c}$ Skaggs School of Pharmacy and Pharmaceutical Sciences, University of California, San Diego \\ Submitted January 25, 2016; accepted April 20, 2016; published May 2017.
}

Objectives. To measure the level of burnout among pharmacy practice faculty members at US colleges and schools of pharmacy and to identify factors associated with burnout.

Methods. Using a cross-sectional, electronic, anonymous survey-design, we measured faculty burnout $(n=2318)$ at US colleges and schools of pharmacy using the Maslach Burnout Inventory-Educators Survey (MBI-ES), which measures burnout dimensions: emotional exhaustion, depersonalization, and personal accomplishment. We assessed MBI-ES scores, demographics and possible predictors of burnout.

Results. The response rate was $32.7 \%(n=758)$. Emotional exhaustion was identified in $41.3 \%$ and was higher in women, assistant professors, and those without a hobby. Participants without a mentor had higher scores of depersonalization. Those with children ages 1-12 years had higher emotional exhaustion and depersonalization compared to those with older children.

Conclusion. Pharmacy practice faculty members at US colleges and schools of pharmacy are suffering from burnout, exhibited mainly through emotional exhaustion.

Keywords: burnout, pharmacy practice faculty, stress

\section{INTRODUCTION}

Burnout is a pathological syndrome in which emotional depletion and maladaptive detachment develop secondary to chronic occupational stress. ${ }^{1}$ It may be associated with a decline in mental and physical health, as well as work performance. Additionally, burnout has been associated with conditions such as depression, suicide, and substance abuse.

The Maslach Burnout Inventory (MBI) measures the three dimensions of burnout (emotional exhaustion, depersonalization and cynicism, feelings of inefficacy) and is the gold standard for assessing burnout in medical research. ${ }^{1-5}$ This model defines "emotional exhaustion" as the stress component of burnout, in which an individual feels depleted of one's emotional and physical resources without any source of replenishment. "Depersonalization" represents the interpersonal dimension of burnout, where an individual

Corresponding Author: Shareen Y. El-Ibiary, College of Pharmacy, Glendale Midwestern University, 19555 N. $59^{\text {th }}$ Ave., Glendale, AZ 85308. Tel: 623-572-3512. Fax: 623-5723550. E-mail: selibi@midwestern.edu

Note: At the time of project completion, Lily Yam was a student at the College of Pharmacy, Glendale Midwestern University. displays a distant attitude toward work and colleagues and is presumed to be a direct response to exhaustion. "Inefficacy" measured by perception of personal accomplishment, represents the self-evaluation aspect of burnout and refers to the belief that one is incompetent and lacks productivity at work. ${ }^{3,4}$ Of the three versions of the MBI Survey, the MBIEducators Survey (MBI-ES) is designed for individuals working in education. ${ }^{3,6} \mathrm{~A}$ high subscore in emotional exhaustion or depersonalization is suggestive of clinically significant burnout. ${ }^{7}$

Burnout is a serious issue affecting individuals working in the health profession and higher education fields. ${ }^{8-15}$ To our knowledge, there is limited recent evidence for the systematic assessment of burnout among pharmacy practice faculty in the United States with very little published in academic pharmacy since the early 1990s. ${ }^{9,10,16,17}$ Assessing burnout among this population is important to identify associated factors and to develop strategies that can help reduce or prevent burnout. We aimed to assess the prevalence of burnout among pharmacy practice faculty using the MBI-ES and to identify predictive factors contributing to burnout.

\section{METHODS}

In August 2014, we measured burnout in pharmacy practice faculty members at US colleges and schools of 


\section{American Journal of Pharmaceutical Education 2017; 81 (4) Article 75.}

pharmacy using a cross-sectional, voluntary, anonymous survey-design. ${ }^{6}$

We emailed a link to the MBI-ES with supplemental demographic questions to individuals listed on the 2014 American Association of Colleges of Pharmacy (AACP) pharmacy practice roster at the lecturer/instructor, assistant, associate, and full professor levels at US colleges and schools of pharmacy. Along with the survey, we also provided information on the research scope. Completion of the survey served as consent. A raffle for two $\$ 100$ gift cards was utilized as incentive for participation. Participants were able to submit an email address for the raffle drawing that was not linked to survey results. Nonresponders were emailed two weeks after baseline. Faculty whose emails were not returned to the investigators as "undeliverable" were considered to have received the survey. Faculty who did not respond to at least one question on the MBI-ES (items 1-22) were excluded from analysis.

The MBI-ES questions were divided into each subscale $($ Emotional Exhaustion $=E E$, Depersonalization $=D P$, Personal Accomplishment $=\mathrm{PA}$ ). The average rating of each subscale was calculated by dividing the total score by the number of completed items. The EE subscale contained nine items, the DP subscale had five items, and the PA subscale had eight items. In EE and DP, low scores were seen as favorable, but in PA, low scores were seen as unfavorable. Scoring on the MBI-ES subscales are as follows: EE as 0-16 (low), 17-26 (moderate) and 27 or higher (high); DP as 0-6 (low), 7-12 (moderate) and 13 or higher (high); and PA as 0-30 (low), 31-36 (moderate) and 37 or higher (high).

De-identified data were collected via Qualtrics version 60949 (Provo, Utah) and analyzed with IBM SPSS Statistics, Version 22.0 (Armonk, NY). No personal identifiers were linked to survey results to ensure privacy. Data were password-protected and maintained by the investigators. Descriptive statistics (mean, median, standard deviations, range were used to evaluate the primary outcome. Student $t$-tests, chi-square and ANOVA were used to analyze associations between MBI scores and predictive factors (eg, gender, hobbies, mentor, children, marital status, academic rank) associated with faculty burnout. The study was approved by the Midwestern University and UCSD Institutional Review Boards.

\section{RESULTS}

Of the 2318 subjects, 758 responded to the survey request (32.7\% response rate) (Table 1). Majority of respondents were female, Caucasian, married, had children, and were in non-tenure tracks. Most respondents were assistant or associate professors ( $>80 \%$ combined). Equal numbers were at public and private institutions, and most respondents were at institutions that were established more than 10 years. More than $60 \%$ of respondents reported having a mentor; of those who had a mentor, majority had informal relationships.

Among the respondents, the mean scores ( \pm standard deviation) on the MBI-ES for EE, DP and PA are displayed in Table 2 . More than $40 \%$ of faculty had scores considered "high" for EE. Only about $10 \%$ of faculty had "high" scores on the DP subscale while about $24 \%$ of faculty had "low" scores on the PA subscale.

Mean scores on the MBI subscales were analyzed for potential predictive characteristics (Table 3). Women had significantly higher EE and lower PA scores compared with men. Those without a hobby had significantly higher EE and DP scores and lower PA scores. Those without a mentor had significantly higher EE scores and DP scores. Having children produced varying results in that those with children had lower levels of EE compared with those without children. However, those with young children (ages 1-12) had higher EE and DP and lower PA scores compared with those without young children.

Scores on EE, DP and PA differed based on academic rank ( $\mathrm{df}=3, p<.05$ for all scores). In post-hoc analysis using Bonferroni correction (significance at 0.125 level), assistant professors had 5.1 mean higher scores $(p=.001)$ and associate professors had 3.8 mean higher scores on $\mathrm{EE}(p=.03)$ compared with full professors. On DP scores, assistant professors had 1.7 mean higher scores $(p=.02)$ compared with full professors. For PA scores, associate professors had 2.3 mean lower scores $(p=.02)$ compared with full professors. We also found a negative correlation between total years worked after pharmacy graduation to average EE and DP scores ( $p<.001$ for both) and a positive correlation with PA scores $(p<.001)$.

Faculty working in newer colleges/schools were associated with worse scores on DP and PA. Those who worked at colleges/schools established fewer than five years had higher DP scores than faculty at schools established 5-10 years $(p=.02)$ and more than 10 years $(p=.008)$. Faculty at colleges/schools established fewer than five years had lower DP scores than those at schools established $5-10$ years. $(p=.03)$.

Figure 1 shows the EE, DP, and PA scores depending on the reported average workweek. In a one-way ANOVA analysis, EE scores were significantly associated $(p<.001)$ with increased workweek hours. In post-hoc analysis using Bonferroni correction $(\mathrm{df}=2$, significance at $p<.02)$, those who worked $>50$ hours per week had higher EE scores compared to those who worked $<20-40$ hours per week $(p<.001)$ and those who worked 41-50 hours per week $(p<.001)$.

Faculty with administrative titles did not have significantly worse scores on EE, DP or PA than those without 


\section{American Journal of Pharmaceutical Education 2017; 81 (4) Article 75.}

administrative roles. Having a primary care provider was not predictive of worse EE, DP or PA scores. Tenure status also did not significantly affect the EE, DP or PA scores.

\section{DISCUSSION}

Our study demographics with high percentage of women, assistant professors and Caucasians are representative of the pharmacy practice faculty in the US. ${ }^{18}$ In addition, we had equal numbers of private and public institutions represented, also resembling the AACP membership. ${ }^{19}$ The age distribution in our sample was also representative of pharmacy practice faculty with $40.4 \%$ of faculty in the 30-39 age range, followed by $21.4 \%$ in the $40-49$ year age group and $20.7 \%$ in the greater than 50 year age group. ${ }^{18}$

In one of the earliest studies conducted on pharmacy faculty burnout, Jackson and colleagues reported that $16.4 \%$ of faculty had high EE, $16.8 \%$ had high DP and $35.8 \%$ had low PA scores. ${ }^{10}$ In our study, the rate of burnout more than doubled, with $41.3 \%$ of participants reporting high EE scores. In addition, mean EE scores were higher than those reported in the Jackson and colleagues' study (24.3 vs. 18.8); but similar for DP (6.3 vs. $6.5)$ and PA (35.3 vs. 36.3) scores. In the normative data from the MBI developers, the mean EE, DP and PA scores among teachers were $21.3,11$ and 33.5 , respectively. ${ }^{6}$ Pharmacy faculty in our study had higher EE scores and lower DP scores. The PA scores were similar to the normative group. ${ }^{7}$

These differences could be due to the fact that our study only included pharmacy practice faculty compared to all pharmacy faculty surveyed in the previous study. We also used the MBI Educators Survey (MBI-ES) (survey used "student" instead of "recipient") although it is uncertain which version was used in the Jackson and colleagues study. Pharmacy practice faculty are heavily involved in clinical activities ( $77.6 \%$ in our sample) which could add to increased stress and burnout. The normative samples reported mean scores (SD) for pharmacists licensed in the US for EE, DP and PA were 21.1 $\pm 11.7,8.0 \pm 6.0$ and $34.2 \pm 8.1$, respectively. ${ }^{12}$ Our study found worse mean scores in all sub-domains. Burnout has been extensively studied among health care providers; in a national survey of US physicians, $37.9 \%$ reported high EE scores. ${ }^{1,8,9,13,20-23}$ Our sample of pharmacy faculty differed from physicians on the DP and PA scores; $10.4 \%$ of pharmacy faculty had high DP scores compared to $29.4 \%$ of physicians and $24 \%$ of pharmacy faculty had low PA scores compared to $12.4 \%$ of physicians reporting low PA scores. These differences could be due to different job expectations and motivations between pharmacy faculty and physicians. For example,
PA is less related to EE and more related to control, freedom, and autonomy in the workplace. ${ }^{16}$ Physicians may have more autonomy in their clinical practice whereas pharmacy practice faculty may be limited in their job responsibilities and in their clinical practice. A similar pattern was seen among nurses where job demands had the most significant impact on EE. ${ }^{13}$

Compared to the previous study and demographic norms for the MBI subscales, EE scores were higher for both men and women pharmacy faculty in our study. ${ }^{6}$ Between genders, it is not surprising the women had higher EE, which is consistent with previous studies and the continuing role conflicts that may exist for women in the workplace and home. ${ }^{17,24-26}$

The mean EE scores for the age groups $\leq 30,31-40$, 41-50 and $\geq 51$ in our study were consistently higher than demographic norms $(23.9,22.3,20.2$ and 18, respectively) and the previous pharmacy faculty study (22.4, 21.5, 18.6, 14.7, 14.4; age groups ranged from 20-29, $30-39,40-49,50-59$ and $>60$ ). The notable difference between our study and the previous Jackson study is that our study showed similar EE scores across the age groups instead of declining as age increased. ${ }^{10}$

In our study, we found that age was not predictive of higher EE scores although those in the assistant professor rank were significantly higher on EE scores. Age may not be directly related to higher EE scores due to the wide age range among junior faculty. Among pharmacy faculty, rank may be more predictive of burnout and EE than age. Another study also found that there was little difference between those in different academic ranks and work and non-work role conflicts. ${ }^{26}$

The mean DP scores for the age groups were lower than the demographic norms $(9.4,8.3,6.7,5.3)$. The PA scores for the age groups in our study were similar to the demographic norms $(35.9,37.3,38.2,38.4)$ and previous pharmacy faculty study $(36.1,35.2,37.2,37,36.8)$.

The mean EE scores for single, married, and divorced/separated in our study were higher than in the Jackson study (23.9 (single), 18.1 (married), 20 (divorced) and 13.3 (separated)) and higher than the normative samples (24.3 (single), 20 (married), 22.3 (divorced) and 23 (other)). ${ }^{7,10}$ The higher scores for single and divorced/separated faculty were attributed possibly due to younger faculty being non-tenured, having lower salaries and having less social support to discuss job-related issues. ${ }^{10,26}$ Non-work influences (eg, marital status, number of children), work influences (eg, time spent at work, academic rank), and gender may contribute to role conflict that ultimately determines overall life satisfaction. ${ }^{26}$ The mean DP scores were lower in our study compared to the demographic norms for single, married and divorced. 


\section{American Journal of Pharmaceutical Education 2017; 81 (4) Article 75.}

Table 1. Demographics of Respondents ${ }^{\mathrm{a}}$

\begin{tabular}{|c|c|}
\hline Survey Item & Respondents (\%) \\
\hline Survey response rate & $758 / 2318(32.7)$ \\
\hline \multicolumn{2}{|l|}{ Gender $(n=751)$} \\
\hline Male & $239(31.8)$ \\
\hline Female & $512(68.2)$ \\
\hline Mean age $(\mathrm{SD})(\mathrm{yrs})(\mathrm{n}=744)$ & 41.0 (10.8 years) (range: $21-75)$ \\
\hline Ethnicity $(\mathrm{n}=758)$ & Respondents (\%) \\
\hline Caucasian & $631(83.2)$ \\
\hline Asian & $60(7.9)$ \\
\hline African-American/Black & $29(3.8)$ \\
\hline Hispanic/Latino & $14(1.8)$ \\
\hline American Indian/Alaska Native & $8(1.1)$ \\
\hline Other & $16(2.1)$ \\
\hline \multicolumn{2}{|l|}{ Current marital status $(n=745)$} \\
\hline Single & $121(16.2)$ \\
\hline Married & $567(76.1)$ \\
\hline Divorced/separated & $28(3.8)$ \\
\hline Co-habitating & $26(3.5)$ \\
\hline Widowed/widower & $3(0.4)$ \\
\hline Has Children $(n=748)$ & $473(63.2)$ \\
\hline Has children aged $1-12(\%$ among those with children $)(n=471)$ & $303(64.3)$ \\
\hline Has child $<1$ year of age ( $\%$ among those with children $)(n=465)$ & $51(11.0)$ \\
\hline \multicolumn{2}{|l|}{ Academic Rank $(n=747)$} \\
\hline Instructor/Lecturer & $17(2.3)$ \\
\hline Assistant Professor & $360(48.2)$ \\
\hline Associate Professor & $253(33.9)$ \\
\hline Professor & $117(15.7)$ \\
\hline Has administrative title $(n=746)$ & $197(26.4)$ \\
\hline \multicolumn{2}{|l|}{ Tenure Status $(\mathrm{n}=745)$} \\
\hline Non-tenured, non-tenure track & $516(69.3)$ \\
\hline Non-tenured, tenure track & $103(13.8)$ \\
\hline Tenured & $126(16.9)$ \\
\hline \multicolumn{2}{|l|}{ Type of Institution $(\mathrm{n}=746)$} \\
\hline Private & $373(50.0)$ \\
\hline Public & $373(50.0)$ \\
\hline \multicolumn{2}{|l|}{ Length of time college/school in existence $(n=744)$} \\
\hline Less than 5 years & $68(9.1)$ \\
\hline $5-10$ years & $123(16.5)$ \\
\hline More than 10 years & $553(74.3)$ \\
\hline \multicolumn{2}{|l|}{ Length of pharmacy program $(n=745)$} \\
\hline 3 years & $83(11.1)$ \\
\hline 4 years & $662(88.9)$ \\
\hline \multicolumn{2}{|l|}{ Current annual salary $(n=743)$} \\
\hline$<\$ 90,000$ & $36(4.8)$ \\
\hline$\geq \$ 90,000$ & 707 (95.2) \\
\hline Mean total years worked after pharmacy school graduation $(\mathrm{SD})(\mathrm{n}=746)$ & 15.1 (10.9 years) (range: $1-48)$ \\
\hline Mean total years (SD) worked at current institution $(n=749)$ & 8.9 (7.8 years) (range: $1-46)$ \\
\hline Average workweek (hours) $(\mathrm{n}=749)$ & Respondents (\%) \\
\hline$<20-40$ & $41(5.5)$ \\
\hline $41-50$ & $362(48.3)$ \\
\hline$>50$ & $346(46.2)$ \\
\hline Has a clinical practice site $(n=746)$ & $579(77.6)$ \\
\hline
\end{tabular}




\section{American Journal of Pharmaceutical Education 2017; 81 (4) Article 75.}

Table 1. (Continued)

\begin{tabular}{lc}
\hline Survey Item & Respondents (\%) \\
\hline Median hours per week devoted to clinical site & 20 (IQR: 15,28$)$ \\
Has didactic teaching responsibilities $(\mathrm{n}=747)$ & $688(92.1)$ \\
Median hours over one year devoted to didactic teaching & 120 (IQR: 60,350) \\
Current position description ( $=745)$ & $606(81.3)$ \\
Fully funded by college/school & $123(16.5)$ \\
Partially funded by college/school/clinical site & $10(1.3)$ \\
Fully funded by clinical site & $6(0.8)$ \\
Other & $471(63.4)$ \\
Has a mentor (n=743) & $397(84.3)$ \\
Within institution $(\%$ of those with mentor) & $205(43.5)$ \\
Outside institution (\% of those with mentor) & $166(35.2)$ \\
Formal $(\%$ of those with mentor) & $363(77.1)$ \\
Informal (\% of those with mentor) & $192(25.8)$ \\
Frequency of exercise per week (hours) $(\mathrm{n}=745)$ & $253(34.0)$ \\
$0-1$ & $181(24.3)$ \\
$2-3$ & $60(8.1)$ \\
$4-5$ & $59(7.9)$ \\
$6-7$ & $505(67.9)$ \\
$>7$ & $616(82.8)$ \\
Has a regular hobby outside of work $(\mathrm{n}=744)$ & \\
Has a primary care provider (n=744) &
\end{tabular}

${ }^{\mathrm{a}} \mathrm{SD}=$ standard deviation

$\mathrm{IQR}=$ interquartile range

Missing responses less than $2 \%$ for all survey items

The mean PA scores in our study were lower than the demographic norms for the same marital statuses.

Having young children was associated with higher EE scores; inability to achieve work-life balance has been identified previously as a contributor to EE. ${ }^{16,25,27}$ Again, among pharmacy faculty, simply having children may not be as impactful as having young children with respect to EE. Having dependent children may also depend on marital status; single faculty with children had lower overall life satisfaction when compared to married faculty with children, married faculty without children and single faculty without children. ${ }^{26}$ Considering the demographic

Table 2. Respondent Overall MBI Scores and Domain Scores ${ }^{\mathrm{a}-\mathrm{d}}$

\begin{tabular}{lccc}
\hline Level and Scale Category & Mean (SD) & Range & Number of respondents (\%) \\
\hline Emotional Exhaustion $^{\text {a,d }}$ & $24.3(12.3)$ & $0-54$ & $227(29.9)$ \\
$\quad$ Low & & & $218(28.8)$ \\
$\quad$ Moderate & & & $313(41.3)$ \\
$\quad$ High & $6.30(5.4)$ & $0-30$ & $552(72.8)$ \\
Depersonalization & b,d & & $127(16.8)$ \\
$\quad$ Low & & & $79(10.4)$ \\
$\quad$ Moderate & $35.3(7.10)$ & $12-48$ & $181(23.9)$ \\
$\quad$ High & & & $217(28.6)$ \\
Personal Accomplishment & \\
$\quad$ Low & & & $359(47.4)$ \\
$\quad$ Moderate & & & \\
$\quad$ High & & & \\
\hline
\end{tabular}

$\mathrm{SD}=$ standard deviation

${ }^{a}$ Emotional exhaustion scores range 0-16 (low), 17-26 (medium), 27 or higher (high);

${ }^{\mathrm{b}}$ Depersonalization scores range 0-6 (low), 7-12 (medium), 13 or higher (high);

${ }^{c}$ Personal Accomplishment scores range 0-30 (low), 31-36 (medium), 37 or higher (high)

${ }^{\mathrm{d}}$ High scores on emotional exhaustion and depersonalization reflect worse scores; low scores on personal accomplishment indicate worse scores 
American Journal of Pharmaceutical Education 2017; 81 (4) Article 75.

Table 3. Predictive Characteristics for Domains of Burnout

\begin{tabular}{|c|c|c|c|c|c|c|}
\hline & $\begin{array}{l}\text { Mean Emotional } \\
\text { Exhaustion } \\
\text { Scores (range) }\end{array}$ & $p$ value & $\begin{array}{c}\text { Mean } \\
\text { Depersonalization } \\
\text { Scores (range) }\end{array}$ & $p$ value & $\begin{array}{l}\text { Mean Personal } \\
\text { Accomplishment } \\
\text { Scores (range) }\end{array}$ & $p$ value \\
\hline \multicolumn{7}{|l|}{ Gender } \\
\hline Male & $22.1(12.9)$ & \multirow[t]{2}{*}{.001} & $6.2(5.5)$ & \multirow[t]{2}{*}{.91} & $36.3(7.1)$ & \multirow[t]{2}{*}{$<.05$} \\
\hline Female & $25.3(11.9)$ & & $6.3(5.4)$ & & $34.9(7.0)$ & \\
\hline \multicolumn{7}{|c|}{ Age $\left(\right.$ years) ${ }^{\mathrm{a}}$} \\
\hline$\leq 30$ & 24.9 & \multirow[t]{4}{*}{.23} & 6.6 & \multirow[t]{4}{*}{$.02^{\mathrm{b}}$} & 35.5 & \multirow[t]{4}{*}{$.009^{\mathrm{h}}$} \\
\hline $31-40$ & 25.1 & & 6.9 & & 34.6 & \\
\hline $41-50$ & 24.4 & & 5.9 & & 35.0 & \\
\hline$\geq 51$ & 22.5 & & 5.2 & & 37.0 & \\
\hline \multicolumn{7}{|l|}{ Has hobby } \\
\hline Yes & 23.2(11.9) & \multirow[t]{2}{*}{.001} & $5.9(5.2)$ & \multirow[t]{2}{*}{.01} & $36.2(6.8)$ & \multirow[t]{2}{*}{$<.001$} \\
\hline No & $26.5(12.7)$ & & $7.0(5.9)$ & & $33.7(7.3)$ & \\
\hline \multicolumn{7}{|c|}{ Has primary care provider } \\
\hline Yes & $24.1(12.4)$ & \multirow[t]{2}{*}{43} & $6.2(5.4)$ & \multirow[t]{2}{*}{.44} & $35.4(7.1)$ & \multirow[t]{2}{*}{.9} \\
\hline No & 25.1(11.8) & & $6.6(5.6)$ & & $35.5(7.1)$ & \\
\hline \multicolumn{7}{|c|}{ Has mentor } \\
\hline Yes & $23.5(11.4)$ & \multirow[t]{2}{*}{$<.05$} & $5.8(4.9)$ & \multirow[t]{2}{*}{.008} & $35.5(6.9)$ & \multirow[t]{2}{*}{47} \\
\hline No & $25.7(13.6)$ & & $7.0(6.2)$ & & $35.1(7.4)$ & \\
\hline \multicolumn{7}{|c|}{ Has children } \\
\hline Yes & $23.2(12.5)$ & \multirow[t]{2}{*}{.001} & $6.1(5.3)$ & \multirow[t]{2}{*}{.21} & $35.7(7.1)$ & \multirow[t]{2}{*}{.15} \\
\hline No & $26.2(11.7)$ & & $6.6(5.6)$ & & $34.9(7.1)$ & \\
\hline \multicolumn{7}{|c|}{ Has children $1-12$ years } \\
\hline Yes & $24.5(11.7)$ & \multirow[t]{2}{*}{.004} & $6.8(5.4)$ & \multirow[t]{2}{*}{$<.001$} & $34.7(6.9)$ & \multirow[t]{2}{*}{$<.001$} \\
\hline No & $20.9(13.7)$ & & $4.9(5.1)$ & & $37.5(7.1)$ & \\
\hline \multicolumn{7}{|c|}{ Has clinical practice site } \\
\hline Yes & $24.8(11.8)$ & \multirow[t]{2}{*}{.05} & $6.3(5.4)$ & \multirow[t]{2}{*}{.54} & $35.2(6.9)$ & \multirow[t]{2}{*}{.23} \\
\hline No & $22.6(13.7)$ & & $6.0(5.7)$ & & $35.9(7.7)$ & \\
\hline
\end{tabular}

${ }^{\mathrm{a}}$ Mean and range not available for one-way ANOVA analysis

$\mathrm{b}_{31-40}$ different than $\geq 51$

characteristics of pharmacy faculty workforce in the US (young, women, junior rank) and the additive contribution of each factor to burnout, there is a need for intervention.

Emotional exhaustion has been identified as a core feature of burnout. ${ }^{5,28-30}$ The high percentage of pharmacy faculty with significant EE found in our study is concerning. Emotional exhaustion is also most responsive to the organizational environment such as role conflict, role ambiguity, participation in decision-making, reward systems and social support networks. ${ }^{31-38}$ In our study, assistant professors had the highest EE scores compared to other ranks, which was consistent with the Jackson study and others. ${ }^{10,14,25}$ This may be associated with real or perceived inability to participate in decision-making, potential lack of social support as new faculty members and concerns about promotion and academic success. Improvements in faculty governance structure, clear roledelineations and reward systems can be made in colleges and schools of pharmacy to potentially reduce EE and burnout among faculty.
Mentoring is defined as a "symbiotic relationship between the mentor and mentee." " We found those with a mentor had lower scores on DP; social support and professional engagement have been shown to be negatively related to depersonalization and positively associated with personal accomplishment. ${ }^{40}$ While a formal mentoring process increases the probability a mentee will receive some kind of mentorship at the initial phase, informal mentoring cannot be ignored. Since most of our respondents had informal mentor-mentee relationships, our study suggests that any type of social support can decrease feelings of DP and increase feelings of PA. ${ }^{41}$ We did not investigate whether faculty had more than one mentor and the extent or effectiveness of those relationships. Regardless of the nature of mentoring, it has been documented that mentoring can lead to job satisfaction and increased productivity. ${ }^{41-43}$ Supporting and implementing mentoring objectives for each faculty member have been shown to be critical to increase faculty retention. ${ }^{41}$ 


\section{American Journal of Pharmaceutical Education 2017; 81 (4) Article 75.}

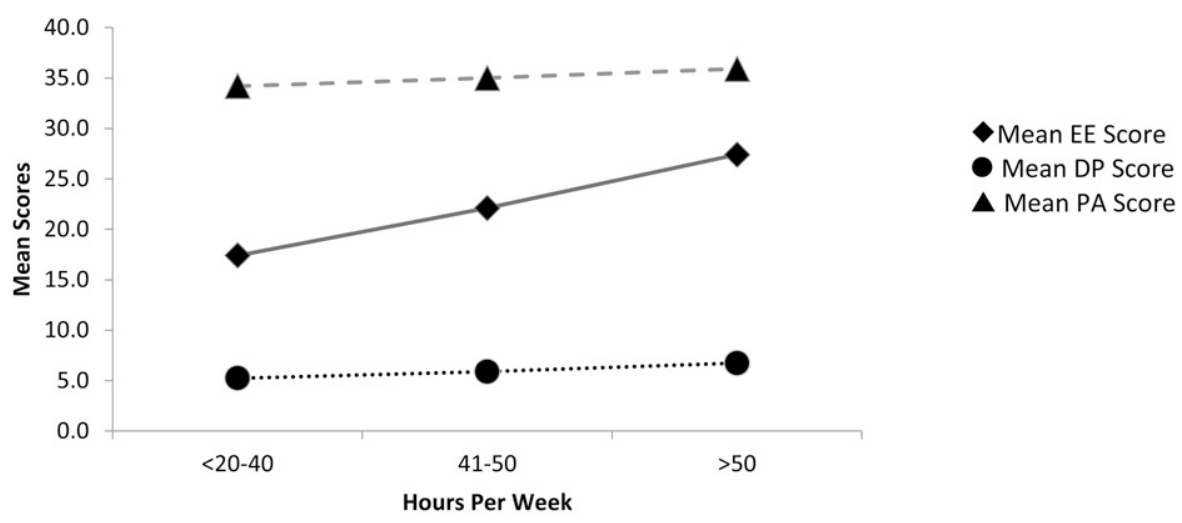

aEmotional exhaustion scores range 0-16 (low), 17-26 (medium), 27 or higher (high); bDepersonalization scores range 0-6 (low), 7-12 (medium), 13 or higher (high); Personal 'Accomplishment scores range 0-30 (low), 31-36 (medium), 37 or higher (high). dHigh scores on emotional exhaustion and depersonalization reflect worse scores while low scores on personal accomplishment indicate worse scores.

Figure 1. Level of MBI-ES Domain Scores ${ }^{\mathrm{a}-\mathrm{d}}$ vs. Mean Workweek Hours

Most faculty reported working more than 40 hours per week, similar to previous reports. ${ }^{26}$ In our study, the number of hours worked correlated linearly with increasing EE scores which contrasted with the previous study. This difference could be due to possibly increasing demands of pharmacy practice faculty and increased expectations within the academic and clinical settings. Time spent at work has been shown to correlate with positive role conflict and negative overall life satisfaction among pharmacy faculty. ${ }^{26}$ Those who reported working more than 48 hours reported doing work-related activities during the evening or weekend/vacation time, spending less time with their family and their job making it difficult for them to be the parent or spouse that they want to be. ${ }^{26}$

Having a primary care provider did not have any correlation with burnout; however, a recent study showed that anxiety and major depressive disorders were reported by $8.8 \%$ and $5.8 \%$ of respondents. ${ }^{44}$ In addition, $15.5 \%$ of respondents reported recent binge alcohol use (five or more drinks on same occasion) and 3.7\% reported heavy alcohol use (five or more drinks on same occasion on five or more days within a month). Assuming that these voluntary figures are underestimations, pharmacy faculty may be at similar risk of mental health and substance use disorders as the general population. ${ }^{44-46}$ Minimal exercise among pharmacy faculty was also confirmed in this study; previously, majority of faculty reported exercising less than 150 minutes per week and spending a significant part of their day in a sedentary environment. ${ }^{45}$

Top five stressors identified among pharmacy faculty are lack of time to perform well, interruptions by students/faculty, handling paperwork, lack of time to meet deadlines, and keeping up with new developments in the profession. ${ }^{10}$ Modification of the workload may help reduce burnout especially among junior faculty. ${ }^{10}$ Flexible work schedules may also be beneficial; annual evaluation of workload is essential since more work hours may be associated with burnout. Mentoring programs should be encouraged especially for junior faculty; however, peer support at all ranks is equally important to promote collegiality and social networks. Establishing clear lines of authority and responsibility, engaging faculty in decision making, and encouraging development of mentor relationships may also help to reduce burnout. ${ }^{37}$ Staff development and counseling, job restructuring, management development and program goals, methods and traditions are also potential strategies to reduce professional burnout. ${ }^{47}$ Self-care (achieving a work-life balance) and finding mentors/role models were provided as guidance/ advice for young women considering careers in academic pharmacy. ${ }^{48}$ Based upon the results of the Wolfgang study, it is suggested that deans and department chairs can help faculty set realistic goals, use time management training programs for faculty who have difficulty in this area, and focus attention on high risk groups such as younger faculty, non-administrative and non-tenured faculty. ${ }^{49}$ Other strategies offered have included mandatory time off, job sharing and incorporating stress-reduction education programs and wellness activities into the workday to reduce sedentary time. ${ }^{45}$

Limitations to our study include a relatively low response rate of $32.7 \%$; however, this is the largest study to date evaluating burnout among pharmacy practice faculty in the US and also matches response rates in similar studies among other health professions' faculty. ${ }^{8-10}$ In addition, the demographics of our responders 


\section{American Journal of Pharmaceutical Education 2017; 81 (4) Article 75.}

are representative of the pharmacy practice faculty in the US similar to the demographics characterized by AACP. ${ }^{18,19}$ As with any survey study, response bias could have occurred and results may be reflective of individuals interested in participating rather than the entire population. It is unknown if non-responders were suffering from burnout and therefore had no time or interest to participate. Conversely, those not suffering from burnout could have chosen not to participate due to disinterest. Our results are also limited to those faculty listed on the AACP roster and this may have excluded other potential participants. In addition, the survey timing may have influenced faculty responses. The survey was administered in the summer when many faculty are on vacation or have lighter teaching loads. In fact, the rate of burnout reported may have been lower during this time and the results may be an underestimation.

\section{CONCLUSION}

Pharmacy practice faculty members at US colleges and schools of pharmacy are suffering from burnout, mainly through emotional exhaustion that is higher than demographic norms. Groups that are at higher risk of emotional exhaustion include women, assistant professors, those with young children, and those who work high number of hours per week. Those with a mentor had lower levels of depersonalization. Programs and resources are needed to assist deans and department chairs at US colleges and schools of pharmacy to reduce or prevent burnout among faculty, especially in high-risk groups. Further research may be conducted to assess whether the impact of faculty burnout has an effect on measurable outcomes, such as depression, substance abuse, and suicidality/violence. Ultimately, the goal is to increase awareness of faculty burnout, prevent or manage burnout among faculty, and improve faculty job satisfaction and retention.

\section{ACKNOWLEDGMENTS}

We would like to thank the Department of Pharmacy Practice, College of Pharmacy-Glendale, Midwestern University for financially supporting this project.

\section{REFERENCES}

1. Thomas NK. Resident burnout. JAMA. 2004;292:2880-2889.

2. Maslach C, Jackson SE, Leiter MP. Maslach Burnout Inventory.

In: Evaluating Stress: A Book of Resources. Lanham, MD: Rowman \& Littlefield Publishers.; 1997:191-218.

3. Maslach C, Schaufeli WB, Leiter MP. Job burnout. Ann Rev

Psychol. 2001;52:397-422.

4. Montero-Marin J, Araya R, Blazquez BO, et al. Understanding

burnout according to individual differences: ongoing explanatory power evaluation of two models for measuring burnout types. BMC Public Health. 2012;12:922.

5. Maslach C. Understanding burnout: work and family issues. In: Halpern DF, Murphy SE, eds. From Work-Family Balance to WorkFamily Interaction: Changing the Metaphor. Hillsdale, NJ: Lawrence Erlbaum; 2005:99-214.

6. Maslach burnout inventory (MBI). Mind Garden. http://www. mindgarden.com/products/mbi.htm Accessed January 13, 2015.

7. Maslach C, Jackson SE, Leiter MP. Maslach burnout inventory manual. 3rd Ed. Palo Alto, CA: Consulting Psychologists Press; 1996.

8. Shanafelt TD, Balch CM, Bechamps GJ, et al. Burnout and career satisfaction among American surgeons. Ann Surg. 2009;250(3):463-471.

9. Shanafelt TD, Boone S, Tan L, et al. Burnout and satisfaction with work-life balance among US physicians relative to the general US population. Arch Intern Med. 2012;172(18):1377-1385.

10. Jackson R, Barnett C, Stajich G, Murphy J. An analysis of burnout among school of pharmacy faculty. Am J Pharm Educ. 1993;57(1):9-17.

11. Lahoz MR, Mason HL. Maslach burnout inventory: factor structures and norms for USA pharmacists. Psychol Rep. 1989;64(3 Pt 2):1059-1063.

12. Gupchup G, Lively B, Holidaygoodman M, et al. Maslach burnout inventory - factor structures for pharmacists in health maintenance organizations and comparison with normative data for USA pharmacists. Psychol Rep. 1994;74(3):891-895.

13. Jourdain G, Chenevert D. Job demands-resources, burnout and intention to leave the nursing profession: A questionnaire survey. Int J Nurs Stud. 2010;47:709-722.

14. Tijdink JK, Vergouwen AC, Smulders YM. Emotional exhaustion and burnout among medical professors; a nationwide survey. BMC Med Educ. 2014;14(1):183.

15. Melendez WA, de Guzman RM. Burnout: the new academic disease. ASHE-ERIC higher education research report no. 9, 1983. Association for the Study of Higher Education; Eric Clearinghouse on Higher Education, Washington, DC.

16. Keeton K, Fenner DE, Johnson TR, Hayward RA. Predictors of physician career satisfaction, work-life balance, and burnout. Obstet Gynecol. 2007;109(4):949-955.

17. Dyrbye LN, Shanafelt TD, Balch CM, Satele D, Sloan J, Freischlag J. Relationship between work-home conflicts and burnout among american surgeons: a comparison by sex. Arch Surg. 2011;146 (2):211-217.

18. American Association of Colleges of Pharmacy. 2014-15 Profile of Pharmacy Faculty. http://www.aacp.org/resources/research/ institutionalresearch/documents/ppf1415-final.Pdf. Accessed November 15, 2015.

19. American Association of Colleges of Pharmacy. Academic pharmacy's vital statistics. http://aacp.org/about/pages/vitalstats. aspx. Accessed December 11, 2015.

20. Vahey DC, Aiken LH, Sloane DM, Clarke SP, Vargas D. Nurse burnout and patient satisfaction. Med Care. 2004;42 (2 Suppl):1157-1166.

21. Alacacioglu A, Yavuzsen T, Dirioz M, Oztop I, Yilmaz U. Burnout in nurses and physicians working at an oncology department. Psychooncology. 2009;18(5):543-548.

22. Roth M, Morrone K, Moody K, et al. Career burnout among pediatric oncologists. Pediatr Blood Cancer. 2011;57(7):1168-1173. 


\section{American Journal of Pharmaceutical Education 2017; 81 (4) Article 75.}

23. Kimo Takayesu J, Ramoska EA, Clark TR, et al. Factors associated with burnout during emergency medicine residency. Acad Emer Med. 2014;21(9):1031-1035.

24. Gunasingam N, Burns K, Edwards J, Dinh M, Walton M. Reducing stress and burnout in junior doctors: the impact of debriefing sessions. Postgrad Med J. 2015;91(1074):182-187. 25. Dyrbye LN, West CP, Satele D, Sloan JA, Shanafelt TD. Work/ home conflict and burnout among academic internal medicine physicians. Arch Intern Med. 2011;171(13):1207-1209.

26. Nair K, Gaither C. Effects of work, non work, and role conflict on the overall life satisfaction of pharmacy faculty. Am J Pharm Educ. 1999;63(1):1-11.

27. Lowenstein SR, Fernandez G, Crane LA. Medical school faculty discontent: prevalence and predictors of intent to leave academic careers. BMC Med Educ. 2007;7:37.

28. Schaufeli W, Taris T. The conceptualization and measurement of burnout: common ground and worlds apart. Work \& Stress. 2005;19

(3):256-262 .

29. Shirom A. Job-related burnout: a review. In: Handbook of Occupational Health Psychology. Washington, DC: American Psychological Association; 2003:245-265.

30. Brenninkmeijer V, Vanyperen N. How to conduct research on burnout: advantages and disadvantages of a unidimensional approach in burnout research. Occup Environ Med. 2003;60(Suppl 1):i16-i20. 31. Anderson MBG, Iwanicki EF. Teacher motivation and its relationship to burnout. Educ Adm Quar. 1984;20(2):109-132. 32. Byrne BM. Burnout - testing for the validity, replication, and invariance of causal-structure across elementary, intermediate, and secondary teachers. Amer Ed Res J. 1994;31(3):645-673.

33. Crane SJ, Iwanicki EF. Perceived role conflict, role ambiguity, and burnout among special education teachers. Remedial Special Educ. 1986;7(2):24-31.

34. Farber BA, Wechsler LD. Crisis in Education: Stress and Burnout in the American Teacher. San Francisco, CA: Jossey-Bass; 1991. 35. Hubert JA, Gable RK, Iwanicki EF. The relationship of teacher stress to school organizational health. In: Advances in Research and Theories of School Management and Policy. Greenwich, CT.: JAI Press; 1990:185-207.
36. Schwab RL, Iwanicki EF. Perceived role conflict, role ambiguity, and teacher burnout. Educ Adm Quar. 1982;18(1):60-74.

37. Schwab RL, Jackson SE, Schuler RS. Educator burnout: sources and consequences. Educ Res Quar. 1986;10(3):14-30.

38. Gaither CA, Nadkarni A, Mott DA, et al. Should I stay or should I go? The influence of individual and organizational factors on pharmacists' future work plans. J Am Pharm Assoc (2003). 2007;47 (2):165-173.

39. Haines S. The mentor-protege relationship. Am J Pharm Educ. 2003;67(3):Article 82.

40. Schaufeli WB, Salanova M, Gonzalez-Roma V, Bakker AB. The measurement of engagement and burnout: a two sample confirmatory factor analytic approach. J Happiness Stud. 2002;3(1):71-92.

41. Fuller K, Maniscalco-Feichtl M, Droege M. The role of the mentor in retaining junior pharmacy faculty members. Am J Pharm Educ. 2008;72(2):Article 41.

42. Carter O, Nathisuwan S, Stoddard GJ, Munger MA. Faculty turnover within academic pharmacy departments. Ann

Pharmacother. 2003;37(2):197-201.

43. Roch GR. Much ado about mentors. Harv Bus Rev. 1979;57 (1):14-20.

44. Kenna G, Wood MD. Substance use by pharmacy and nursing practitioners and students in a northeastern state. Am J Health Syst Pharm. 2004;61(9):921-930.

45. Lindfelt TA, Ip EJ, Barnett MJ. Survey of career satisfaction, lifestyle, and stress levels among pharmacy school faculty. Am J Health Syst Pharm. 2015;72(18):1573-1578.

46. Kessler RC, Berglund P, Demler O, et al. The epidemiology of major depressive disorder: results from the national comorbidity survey replication (NSC-R). JAMA. 2003;289(23):3095-3105.

47. Cherniss C. Professional Burnout in Human Service Organizations. New York, NY: Praeger Publishers; 1980. 48. Chisholm-Burns MA, Spivey CA, Billheimer D, et al. Multiinstitutional study of women and underrepresented minority faculty members in academic pharmacy. Am J Pharm Educ. 2012;76(1):7. 49. Wolfgang AP, Ortmeier BG. Career commitment, career plans, and job-related stress - a follow-up-study of pharmacy students as pharmacists. Am J Pharm Educ. 1993;57(1):25-28. 